\title{
Histopatolojik Görüntülerde Kanser Tespit ve Lokasyon Yöntemleri
}

\author{
Zehra Bozdağ Karakeçi ${ }^{1 *}$, Muhammed Fatih Talu ${ }^{2}$ \\ 1* İnönü Üniversitesi, Mühendislik Fakültesi, Bilgisayar Mühendisliği Bölümü, Malatya, Türkiye, (ORCID: 0000-0002-1119-5275), zbozdag @ harran.edu.tr \\ 2 İnönü Üniversitesi, Mühendislik Fakültesi, Bilgisayar Mühendisliği Bölümü, Malatya, Türkiye, (ORCID : 0000-0003-1166-8404), fatihtalu@ gmail.com
}

(İlk Geliş Tarihi 1 Şubat 2021 ve Kabul Tarihi 9 Nisan 2021)

(DOI: 10.31590/ejosat.888836)

ATIF/REFERENCE: Bozdă̆, Z, Talu, M.F, (2021). Histopatolojik Görüntülerde Kanser Tespit ve Lokasyon Yöntemleri. Avrupa Bilim ve Teknoloji Dergisi, (23), 608-616.

\section{$\ddot{O} \mathbf{z}$}

Meme lenf düğ̈̈mlerinin histopatolojik görüntülerinde tümör tespiti meme kanseri teşhisinde en önemli bulgulardan bir tanesidir. Histopatolojik görüntüler, patologlar tarafindan dikkatli bir şekilde incelenerek tümör tespiti yapılır. Bu işlem hem iş yükü yoğunluğuna hem de sübjektif bir değerlendirmeye neden olmaktadır. Histopatolojik görüntülerde tümörün otomatik tespiti için International Symposium on Biomedical Image (ISBI) tarafından CAMELYON16 veri seti kullanılmıştır. Tüm slayt görüntülerin (TSG) farklı seviye çözünürlüklerinde oluşturulan veri setleri Faster RCNN kullanarak analiz edilmiştir. TSG 'nün 3. çözünürlük seviyesinden oluşturulan farklı görüntü boyutuna sahip veri setleri ise Mask RCNN kullanılarak analiz edilmiştir. Son olarak ISBI'da dereceye giren HMS\&MIT yöntemi kısıtlı bir veri seti üzerinde uygulanmış ve histopatolojik görüntü veri setlerindeki performansı Faster RCNN ve Mask RCNN algoritmaları ile karşılaştırılmıştır. Mask RCNN (\%57 AUC) düşük çözünürlüklü seviyeli görüntülerle (3. seviye) eğitilmiş olmasına rağmen, HMS ve MIT (\%58 AUC) (yüksek çözünürlüklü seviyeli görüntüler kullanılarak, 0 . seviye) yöntemine yakın bir doğruluk değerine sahiptir. Ayrıca bir TSG analizi için, sonuç mümkün olan en kısa sürede (0,58 saat) Faster RCNN ile elde edilmiştir.

Anahtar Kelimeler: Görüntü Bölütleme, Derin Öğrenme, Faster RCNN, Medikal Görüntü İşleme, Mask RCNN, Nesne Tespiti, Tümör Tespiti.

\section{Cancer Detection and Location Methods in Histopathological Images}

\begin{abstract}
Tumor detection in the histopathological images of breast lymph nodes is one of the most important findings in the diagnosis of breast cancer. Histopathological images are carefully examined by pathologists and tumor detection is performed. This process causes both workload density and a subjective assessment. The CAMELYON16 dataset has been used by the International Symposium on Biomedical Image (ISBI) for automatic detection of the tumor on histopathological images. Data sets created at different level resolutions of whole slide images (WSI) have been analyzed using Faster RCNN. The data sets with different image sizes created from 3rd resolution levels of WSI have been analyzed using Mask RCNN. Finally, the HMS \& MIT method, which ranked in ISBI, has been applied on a limited data set, and its performance on the histopathological image data sets has been compared with the Faster RCNN and Mask RCNN algorithms. Although Mask RCNN (57\% AUC) has been trained with low-resolution level images (3rd levels) has an accuracy value close to the HMS \& MIT (58\% AUC) (using high-resolution level images, Oth level) method. Also, for a WSI analysis, the result has been obtained with Faster RCNN as soon as possible ( 0.58 hours)
\end{abstract}

Keywords: Semantic Segmentation, Deep Learning, Faster RCNN, Medical Image Processing, Mask RCNN, Object Detection, Tumor Detection.

\footnotetext{
*Sorumlu Yazar: zbozdag@harran.edu.tr
} 


\section{Giriş}

Meme kanseri tüm dünyada kadınlarda en s1k görülen kanser türüdür. 2012 yllındaki verilere göre yeni kanser teşhislerinin \%12'si meme kanseridir. Meme kanseri teşhisinin \%25 kadın bireylerdir. Dünya geneline bakıldığında 4 kadından birine meme kanseri teşhisi konulmaktadır (American Cancer Society, 2019).

Meme kanseri ileri seviye de lenf düğümlerinde tümör oluşturmaktadır. Lenf düğümlerinde tümör oluşması hastalığın seyrini etkileyen en önemli faktörlerden bir tanesidir. Bu nedenle lenf düğümleri hastadan biyopsi ile alınır ve özel işlemlerden geçirildikten sonra 1şıklı mikroskop aracılığıyla incelenir. Böylece hastalığın kesin teşhisi konulur.

Biyopsi ile alınan dokuların analizi yapılır. Doku analizinde, genel doku boyası olarak hematoksilin-eozin boyası (H\&E) kullanılmaktadır. Dokunun histolojik yapısı epitel, lümen, yağ ve stroma yapılarından oluşur. $\mathrm{Bu}$ yapıların rengi, boyutu, şekli dokunun sağlığı hakkında birçok bilgi içermektedir. Biyopsi ile elde edilen doku, birtakım işlemlerden geçirilerek incelenmektedir. $\mathrm{Bu}$ işlemlerden bir tanesi dokunun boyanmasıdır. H\&E boyama geniş kullanımı olan, ucuz doku boyama tekniğidir. Hematoksilin dokudaki çekirdekleri koyu mavimsi ve epitel dokuyu ise açık mor rengine dönüştürmektedir. Eozin ise stromayı pembe rengine dönüştürmektedir. Bu iki boyanın beraber kullanılmasıyla doku yapıları arasındaki kontrast artmakta ve mikroskop ile incelenmesi kolaylaşmaktadır.

Histopatolojik görüntüsü içerisinde kanserli dokuları tespit edilmesi ve lokalizasyonun yapılması hedeflenmektedir. Son birkaç yıldır bilgisayar destekli tespit ve lokalizasyon üzerine çalışmalar yoğunlaşmıştır.

Histopatolojik doku görüntülerinin bilgisayar destekli analizlerinde genellikle iki tip yaklaşım kullanılmaktadır. Birinci yaklaşım yapısal özelliklerin çıkartılması örneğin nükleitlerin veya glandular şekilleri gibi belirgin dokuların bölütlenmesine dayalı çalışmalar (Verma ve ark., 2017, Celik ve ark., 2020; Ishikawa ve ark., 2019). Bir diğer yöntem ise doku gösteriminden (texture representation) yararlanılarak yapilan global yaklaşımlardır. Doku bölütlemenin kolay bir işlem olmadığı ve hatalara olan yatkınlığından dolayı çoğu araştırmada, güncel doku analiz yöntemleri kullanarak sınıflandırma yapılmaktadırlar. Güncel doku analizinde iki farklı yol izlenmektedir. İzlenen yollardan bir tanesi görüntülerin doku, renk özellikleri elde etmek ve bu özellikleri makine öğrenme sınıflandırıcılar yardımıyla analiz etmektir. Diğer bir yol ise makine öğrenme yöntemlerinden biri olan ve son zamanlarda yaygın olarak kullanılan derin öğrenme yöntemidir.

Doku özelliklerinin elde edilmesi ve incelenmesinde; süperpiksel, istatiksel ve temelse özellikleri, Wavelet doku özellikleri, renk-doku özellikleri, Gri Seviye Eş-Oluşum Matrisi (Grey-level Co-occurrence Matrix, GLCM), yerel ikili örüntü (Local Binary Pattern, LBP) gibi klasik özellikler kullanılmaktadır. Elde edilen özellikler Destek Vektör Makineleri (DKM), Rassal Orman (Random Forest) sınıflandırıcı veya yapay sinir ağları (YSA) kullanılmaktadır (Bejnordi ve ark., 2015; Bejnordi ve ark., 2016; Reis ve ark., 2017; Riaz ve ark., 2016; Samah ve ark., 2017; Wan ve ark., 2017).
Son zamanlarda görüntü ile ilgili alanlarda yapılan çalışmalarda, evrişimli sinir ağları (Convolutional Neural Network, CNN) derin öğrenme algoritmaları sıklıkla kullanılmaktadır. $\mathrm{Bu}$ algoritmalar tıbbi görüntülerde de iyi sonuçlar vermektedir. Histopatolojik görüntü analizinde özellikle tümör tespit ve lokasyonunda yapılan birçok çalışma mevcuttur. VGGNet, DenseNet, ScanNET, ResNet ve Slim Inception gibi güncel derin öğrenme algoritmalar kullanılmaktadır(Guo ve ark., 2019; Gupta, ve Bhavsar, 2018; Song ve ark., 2017; Wang ve ark., 2018; Wei ve ark., 2019).

Tüm slayt görüntülerinde (TSG) oluşan CAMELYON16 veri seti kullanılarak çeşitli çalışmalar yapılmıştır. Ye ve ark. SeDenseNet kullanarak görüntünün çözünürlüğü ve tümörlü olup olmadığını tespit etmiştir (Ye ve ark., 2019. Bir değer çalışmada histopatolojik görüntü bölütlemesi için zayıf denetimli öğrenme sistemi geliştirmiştir ve kullanılmıştır (Xu ve ark., 2019).

$\mathrm{Bu}$ çalışmanın amacı güncel nesne tespit ve bölütleme algoritmaları (Faster RCNN, Mask RCNN) kullanarak histopatolojik görüntü analiz sonuç başarılarını incelemektir. CAMELYON16 veri setinden farklı boyut ve çözünürlüklerde histopatolojik görüntüler kullanılarak veri setleri oluşturulmuştur. Veri setleri kullanılarak analizler yapılmış ve algoritmaların performansları değerlendirilmiştir. Son olarak, ISBI dereceye giren HMS\&MIT yöntemi kısıtlı veri seti üzerinde uygulanarak Faster RCNN ve Mask RCNN elde edilen sonuçlar ile karşılaştırılmıştır. Elde edilen sonuçlarda yöntemler birbirlerine yakın seviyelerde doğruluk (Area Under Curve, AUC) vermelerine rağmen Faster RCNN ve Mask RCNN, HMS\&MIT yönteminden hızlı sonuç vermektedir.

Bu çalışmanın sonraki kısımları için Bölüm 2'de kullanılan materyal ve metotlar hakkında detaylı bilgi verilmiştir. Bölüm 3 'te araştırma sonuçları ve tartışma sunulmuştur. Bölüm 4'te deneysel sonuçlar hakkında bilgi verilmiştir ve Bölüm 5'te genel sonuçlar verilmiştir.

\section{Materyal ve Metotlar}

\subsection{Veri Seti}

Çalışmada kullanılan veri seti, 2016 yılında CAMELYON16 adlı yarışmadan elde edilmiştir. Amerika da bulunan Radboud University Medical Center (RUMC) ve University Medical Center Utrecht'den (UMCU) 400 tane TSG toplanmıştır. İki merkezden toplanan görüntüler iki farklı slayt tarayıcıdan elde edilmiştir. Tüm slayt tarayıcıları 40x objektif büyütme olanağına sahiptirler. Görüntüler ortalama 1 Gigabayt büyüklüğünde, 200000x100000 boyutlarında ve farklı çözünürlük seviyelerine sahip TIFF dosya formatındadırlar.

Yarışmanın amacı, meme kanserli hastadan alınan lenf düğümlerinin histopatolojik TSG'lerinde tümör oluşumunun otomatik tespiti ve sınıflandırılmasıdır. Bütün görüntülerdeki tümörlü alanlar uzman patologların gözetiminde belirlenmiştir. Yarışma organizasyonu, tümörlü slaytlardaki tümörün konum bilgilerini içeren XML dosyaları vermiştir. Verilen dosyalar kullanılarak TSG özelliğine sahip maskeler oluşturulmaktadır. Şekil 1 (a)'de TSG örneği verilmektedir (Spanhol ve ark., 2016). Şekilde görüldüğü gibi piramit seviyelidir, her bir seviye bir önceki seviyenin 2 katı çözünürlüğe sahiptir. Genel olarak 8 seviyeli ve $0-7$. seviye olarak adlandırılmaktadırlar. 0 . seviye en alt ve en yüksek çözünürlüğe sahiptir. 7. seviye ise en üst ve en düşük çözünürlüğü sahiptir. Şekil 1'de (b), (c) ve (d)'de 
sırasıyla bir TSG, belirlenen tümörlü alanlar ve TSG'nün maskesi verilmektedir. Yarışma katılımcılara TSG ve tümörlü bölgelerin konumlarını bulundurulan XML dosyalarını vermektedir. Tablo 1'de veri seti boyutu verilmiştir.

Tablo 1. CAMELYON16 veri seti

\begin{tabular}{l|l|l|l}
\hline & Normal & Tümör & Toplam \\
\hline Eğ̈itim & 160 & 111 & 271 \\
\hline Test & 80 & 49 & 129 \\
\hline Toplam & 240 & 160 & 400 \\
\hline
\end{tabular}

Şekil 1. (a) TSG yapısı, (b) TSG örneği, (c) tümörlü alanlar ve (d) maske görüntüsü

\subsection{Değerlendirme Ölçütleri}

ISBI tarafından verilen CAMELYON16 için iki iş tanımı yapmıştır. Birinci iş tanımı, TSG'sünün tümör içerip içermediğine göre sinıflandırılması (slayt tabanlı değerlendirme), ikinci iş tanımı ise her bir TSG'de bağımsız tümör bölgelerinin tespitinin yapılmasıdır (lezyon tabanlı değerlendirme).

\subsubsection{Slayt Tabanlı Değerlendirme}

Verilen TSG'nün içinde tümörlü bölge olup olmadığını tespit edilmesi gerekmektedir. $\mathrm{Bu}$ amaçla, her bir TSG için tümör içerme olasılığı hesaplanacaktır. Değerlendirme için, Bir Alıcı İşlem Karakteristiği (Receiver Operating Characteristic, ROC) eğrisi altında kalan alan ölçüt olarak kabul edilmektedir. Denklem (1), (2) ve (3)’te ROC eğrisinin çizilebilmesi için gerekli denklemler verilmiştir.

$$
\begin{aligned}
& \text { Duyarlılık }=\frac{\text { Gerçek Pozitif }(T P)}{\text { Gerçek Pozitif(TP)+Yanlıs Negatif (FN) }} \\
& \text { Özgüllük }=\frac{\text { Gerçek Negatif }(T N)}{\text { GerçekNegatif }(T N)+\text { YanlışPozitif }(F P)} \\
& \text { Yanlış Pozitif Oranı }=1-\text { özgüllük }
\end{aligned}
$$

TP uygulama sonucu pozitif çıkan gerçek pozitif sayısı; FP uygulama sonucu pozitif çıkan yanlış pozitif sayısı; FN uygulama sonucu negatif çıkan gerçek pozitif sayısı ve TN, uygulama sonucu negatif gerçekte de negatif sayısını belirtmektedirler.

ROC olasılık eğrisidir, bir yöntemin tanı koyma başarısını belirlemek için kullanılır. Bir ROC eğrisi, farklı eşik değerleri için dikey eksen üzerinde gerçek pozitif oranı yani Duyarlılık ile yatay eksen üzerinde Yanlış Pozitif Oranı (1-özgüllük) yer almaktadır. Eğrinin altında kalan alan algoritmaların performanslarını değerlendirmek için ölçüt olarak kullanılır (AUC) (Bejnordi ve ark., 2017). AUC değeri yöntemin sınıfları birbirinde ayırt edebilme kabiliyetini temsil eder. Yüksek AUC değeri sahip bir model, sınıflandırmayı başarılı bir şekilde yapıyor demektir (Fan ve ark., 2006).

\subsubsection{Lezyon Tabanlı Değerlendirme}

TSG içinde birden fazla sayıda tümörlü bölge bulunması durumunda bunların tespit ve lokalizasyonunun yapılmas1 gerekmektedir. Algoritmaların tespit/lokalizasyon performans değerlendirmesi Serbest Alıcı Çalışma Karakteristiği (FreeReceiver Operating Characteristic, FROC) eğrisi kullanılarak yapılmaktadır. FROC, ROC analizine benzerdir, yalnız x ekseni yanlış pozitif oranının yerine slayt başına ortalama yanlış pozitif sayısı kullanılmaktadır. $\mathrm{Bu}$ değerlendirmede, tespit edilen bölgenin konumu verilen gerçek tümörlü bölge içinde ise, gerçek pozitif olarak kabul edilir.

Şayet;

- Tek bir gerçek tümörlü bölge için birden fazla konum tespit edilmişse, bunlar tek bir gerçek pozitif olarak kabul edilmektedir.

- Gerçek tümörlü bölge dışındaki tespitler yanlış pozitif olarak kabul edilmektedir.

FROC eğrisi oluşturulduktan sonra yarışma tarafından belirlenen 6 yanlış pozitif oranlarına karşılık gelen Duyarlılık değerlerinin ortalaması algoritmaların başarısını değerlendirmek için kullanılmaktadır (Görüntü başına düşen yanlış pozitif oranı 1/4, 1/2, 1, 2, 4 ve 8) (Bejnordi ve ark., 2017). ISBI, FROC ve AUC ölçütlerinin hesaplanması için gerekli kodları Ptyhon ve Matlab dillerinde katılımcılara sunmaktadır.

\subsection{HMS\&MIT Yöntemi}

Tümörlü ve normal TSG'lerin 0 . seviyesinde rastgele 256x256 boyutlarında normal ve tümörlü doku parçaları toplanmıştır. Uygulama aşamasında 3,2 milyon dokudan oluşan veri seti hazırlanmıştır. Aynı zamanda görüntü verilerine veri çoğaltma teknikleri (rotasyon, rastgele çevirme, rastgele kırpma ve RGB'nin her bir renk kanalına rastgele ofsetlerin eklenmesi) uygulanmıştır. Orijinal çalışmada boyama normalizasyonu tekniği uygulanmıştır, hazırlanan veri setine boya normalizasyon 
tekniği uygulanmamıştır (Bejnordi ve ark., 2016). HMS\&MIT ekibi çalışmalarında, 22 katmanlı derin öğrenme mimarisi olan GoogleNET kullanılmıştır (Wang ve ark., 2016).

HMS\&MIT, slayt tabanlı değerlendirme için, ağın (GoogleNET) çıkışlarından oluşturulan olasılık haritasının belli özellikleri kullanılmıştır. Olasılık haritası, TSG'nin 0. seviyede alınan 256x256 görüntü sonuçları (tümörlü veya normal olma olasılığı) birleştirilerek, 7. seviyeye denk bir harita oluşturulmaktadır. Olasılık haritasının, bağlı bölgelerin alanları, eksantrikliği, uzatı (bölge alanının toplam sınırlayıcı kutu alanına oranı), sınırlayıcı kutu alanı, ana eksen uzunluğu, bölgenin maksimum, ortalama ve minimum olasılık değerleri, sınırlama kutusunun en-boy oranı, dayanıklılık (bölge dış çevresinin dışbükey alana oranı) özellikleri toplanmaktadır. Rassal Orman sinıflandırıcısı kullanılarak slayt tabanlı sınıflandırma yapılmıştır. Şekil 2'de HMS\&MIT geliştirdiği tümör tespit taslağı verilmiştir (Wang ve ark., 2016).

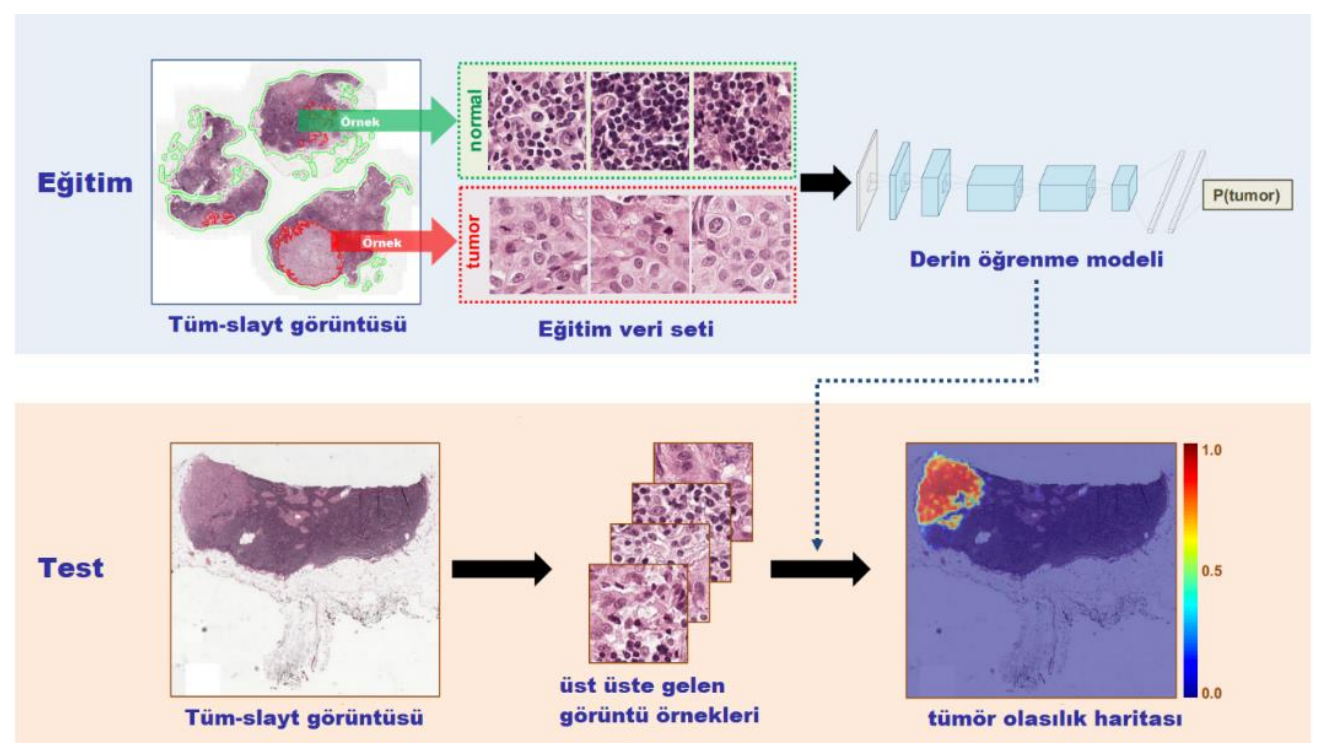

Şekil 2. HMS\&MIT yöntem taslă̆l

\subsection{Faster RCNN}

Faster RCNN nesne tespit algoritmasıdır. Bu algoritmanın temeli Bölgesel Evrişim Sinir A $\breve{1} 1$ (Region Convolutional Neural Network, Region CNN) ve Hizlı Bölgesel Evrişim Sinir Ağ 1 (Fast Region Convolutional Neural Network, Fast CNN) mimarilerine dayanmaktadir.

Region CNN, 2014 yılında Girshick ve ark. tarafından geliştirmiş bir nesne tespit algoritmasıdır (Girshick ve ark., 2016). Görüntü içindeki aday bölgeler (içerisinde nesne bulundurma ihtimali olan bölgeler) Seçici Arama (Selective Search) yöntemi ile elde edilmektedir. VGG-NET veya ResNet gibi derin Evrişim Sinir Ağları (Convolutional Neural Network, CNN) kullanılarak bu aday bölgelerden özellik vektörleri oluşturulmuştur. Son adım da sınıflandırma işlemi için DVM kullanılarak sınıflandırma yapılmıştır.

Fast RCNN, Region-CNN daha hızlı bir yöntem uygulamaktadır. Aday bölgeler CNN'e giriş verisi olarak verilmesi yerine bütün görüntü ilk olarak $\mathrm{CNN}$ verilmektedir. Aday bölgelerin tespiti için CNN çıkışında elde edilen özellik haritalarına SS uygulanmaktadır. Bu çıkışlar ortaklama katmanı (pooling layer) sayesinde önceden belirtilmiş bir çıkış boyutuna indirgenmektedir. Son olarak tamamen bağlantılı evrişim sinir ağına (Fully Connected Convolutional Neural Network, FCNN) giriş verisi olarak verilmektedir. Fast RCNN, aykırı görüntülere daha az hassas olan yeni bir kayı fonksiyonu kullanılmaktadır (Smooth L1 Loss) (Girshick, 2015).

Faster RCNN, Ren ve ark. nesne tespitin önceki mimarilerden daha hızlı ve başarılı bir teknik geliştirilmiştir. Görüntünün özelliklerinin elde edilmesi için daha önceden eğitilmiş derin bir CNN (ResNet-50, ResNet-110 gibi) seçilmiştir. CNN'nin sonuna doğru tamamen bağlantılı katmanlarını çıkartmış, başlangıç katmanları kullanılmıştır. CNN'lerin başlangıç katmanları görüntünün ayırt edici (yüksek seviyeli) özellikleri olan kenar ve renk bilgilerinin öğrenirler. Kafa olarak tanımlanan başlangıç katmanlarının çıkış haritası Bölge Öneri Ağı (Region Proposal Network, RPN) adı verilen bir yapay sinir ağına giriş olarak verilmektedir. RPN, harita içerisinden nesne olma ihtimali olan bölgeleri elde edilmektedir. Böylece hem işlem maliyeti düşürülmekte hem de algoritman önceki çalışmalardan daha hızlı çalışması sağlanmaktadır. RPN çıkışında aday bölgeler içindeki nesnenin sınıflandırılması ve sınır kutusunun elde edilmesi için sınıflandırıcı katmanlar kullanılmaktadır. Ağın eğitilmesi için dört tane kayıp fonksiyonu kullanılmaktadır. İlk iki fonksiyon RPN'deki aday sınır kutuları ve bu aday sınır kutularında nesne olup olmadığı için kullanılan kayıp fonksiyonlarıdır. Diğer iki fonksiyon ise sınıflandırıcı katmandaki nesne sınıflandırma ve sınır kutuları için oluşturulan kayıp fonksiyonlarıdır (Ren ve ark., 2015).

\subsection{Mask RCNN}

Mask RCNN, nesne tespit ve anlamsal bölütleme yapan bir algoritmadir. Bu algoritma, nesne tespiti yapan Faster RCNN algoritmasına bölütleme işleminin eklenmesi ile geliştirilmiştir. Faster RCNN, giriş görüntüsünde tanımlı nesnelerin sınıflarını ve nesneleri çevreleyen çerçevenin (sınır kutusu) konum ve boyut bilgisini vermektedir. Mask RCNN, bunlara ek olarak nesnenin anlamsal maskesinin oluşturmaktadır. Maske oluşturulması için Tamamen Evrişimli A ̆g (Fully Convolutional Network, FCN) kullanılmaktadır. Faster RCNN'de kullanılan kayıp fonksiyonlarına, maske için kullanılan kayıp fonksiyonu da eklenmektedir. Şekil 3'de Faster RCNN ve Mask RCNN 
algoritmalarının taslak görüntüleri verilmektedir (He ve ark.,

2017; Ren ve ark., 2015).

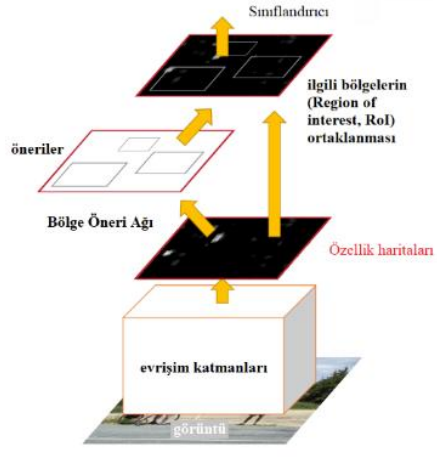

(a)

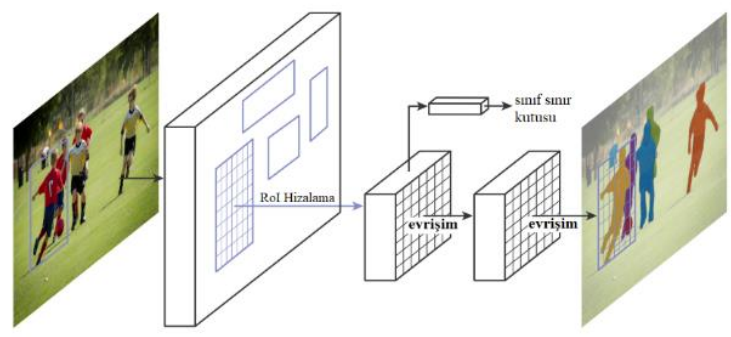

(b)

Şekil 3. (a) Faster RCNN, (b) Mask RCNN

\section{Araştırma Sonuçları ve Tartışma}

\subsection{Faster RCNN}

CAMELYON16 eğitim veri seti içerisinden 111 tümörlü TSG farklı çözünürlük seviyelerinde (3, 4, ve 5 . seviyeler) normal ve tümör dokusu barındıran 256x256 boyutlarında histopatolojik görüntü ve ikili maske görüntüleri hazırlanmıştır. Tablo 2'te farklı çözünürlük seviyelerinde toplanan doku ve maske örnekleri verilmiştir. Toplamda 111 tümörlü TSG'den 3 farklı seviyeye ait sabit boyutlu $(256 \times 256)$ görüntüler hazırlanarak üç veri seti oluşturulmuştur. Bu veri setlerinin \%80 eğitim, \%20 ise test için kullanılmıştır. Faster RCNN ayrı ayrı üç veri seti kullanılarak elde edilen test sonuçları değerlendirilmiştir. Aynı zamanda derin öğrenme modellerinde görüntü özelliklerinin elde edilmesinde omurga (backbone) olarak adlandırılan derin öğrenme mimarileri kullanılmaktadır. Faster RCNN mimarisinde Inception_v2 kullanılmıştır (Chollet, 2017).

Nesne tespitinde standart performans ölçütü olan Ortalama Hassasiyet (Mean Average Precision-mAP) kullanılmıştır. mAP, IoU'nun (Intersection over Unit) farklı eşik değerlerine göre hesaplanır.

IoU, tahmin edilen sınır $\left(B_{t}\right)$ alanı ile gerçek nesne sınırı $\left(B_{g}\right)$ alanının ne kadar örtüştüğümü ölçmek için kullanılan bir ölçüttür. Denklem (4)’te $I o U$ hesaplanması verilmektedir.

$$
I o U=\frac{\operatorname{alan}\left(B_{t} \cap B_{g}\right)}{\operatorname{alan}\left(B_{t} \cup B_{g}\right)}
$$

Önceden belirlenen $I o U$ eşik değerine göre Duyarlılık (Denklem (1)) ve Kesinlik (Denklem (5)) eğrisi oluşturulur. Ortalama Hassasiyet (Average Precision- AP), duyarlılık ve kesinlik eğrisi altındaki toplam alandır. Duyarlılık ve kesinlik değerleri her zaman 0 ile 1 değerleri arasındadırlar. Denklem (6)' te $A P$ hesaplama formülü verilmektedir. $A P$ her bir sınıf için ayrı ayrı hesaplanır. $m A P$, her bir sinıfa ait $A P$ 'nin toplamının toplam sınıf sayısına bölünmesiyle hesaplanır. $r$ kesinlik, $p(r)$ ise kesinlik değerine karşı gelen duyarlılık değeridir. Denklem (7)'da $m A P$ hesaplanması verilmiştir. $N$ sınıf sayısını temsil etmektedir.

$$
\begin{aligned}
& \text { Kesinlik }=\frac{\text { Gerçek Pozitif }(G P)}{\text { Gerçek Pozitif }(\text { GP })+\text { Yanlış Pozitif }(Y P)} \\
& A P=\int_{0}^{1} p(r) d r \\
& m A P=\frac{1}{N} \sum_{i=1}^{N} A P_{i}
\end{aligned}
$$

Tablo 3'te farklı çözünürlük seviyeleri (3., 4., ve 5. seviyeler) kullanılarak elde edilen üç veri seti sonuçlar verilmektedir. Tablonun dördüncü sütununda mAP değeri verilmektedir. mAP, IoU'nun 0.50 ile 0.95 eşik değer aralığında 0.05 eklenerek elde edilen sonuçların $(0.50,0.55,0.60,0.65$, $0.70,0.75,0.80,0.85,0.90,0.95)$ ortalamasidır. Tablo 3 'te görüldüğü gibi en yüksek mAP değerleri 3. seviyede elde edilmiştir.

\subsection{Mask RCNN}

CAMELYON16 eğitim veri setinde 111 tümörlü TSG'nün 3. seviyede tümör ve normal doku içeren farklı boyutlarda $(256 \times 256,512 \times 512$ ve $1024 \times 1024)$ görüntüler toplanmıştır. Tablo 4'te bu görüntülerin farklı boyutlu örneği gösterilmiştir. TSG'lerin 3. seviyesinden farklı boyutlardan oluşturulan üç veri setinin \%80 eğitim, \%20'si test için kullanılmıştır. Mask RCNN algoritmasının üç farklı boyutlu görüntü setleri için elde edilen test sonuçları Tablo 5'te verilmiştir. Mask RCNN mimarisinde Inception_v2 omurga mimarisi olarak kullanılmıştır (Chollet, 2017). Tablodaki değerlendirme ölçütü olan mAP Denklem (6)'da verilmiştir.

Tablo 5'te TSG'nin 3. seviyesinde farklı görüntü boyutlarına göre elde edilen mAP sonuçları verilmiştir. En yüksek mAP değeri 256x256 boyutlu görüntü sonuçlarında elde edilmiştir. 
European Journal of Science and Technology

Tablo 2. TSG'nün farklı çözünürlük seviyelerinde elde edilen doku görüntüleri

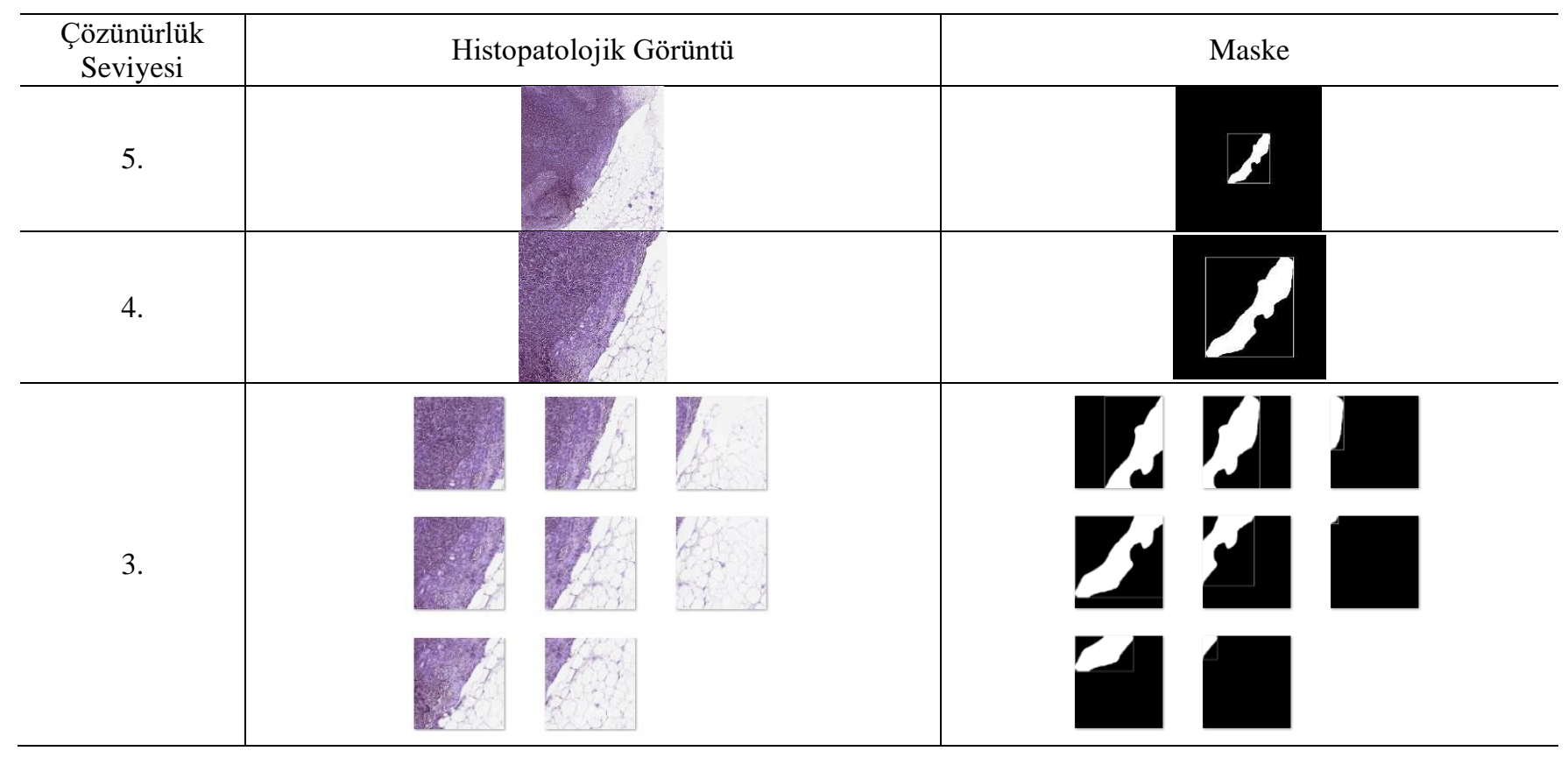

Tablo 3. TSG'sünün farkl çözünürlük seviyeleri kullanılarak oluşturulan 3 veri seti sonuçları

\begin{tabular}{l|l|l|l}
\hline Model & Omurga & $\begin{array}{l}\text { Çözünürlük } \\
\text { Seviyesi }\end{array}$ & mAP \\
\hline Faster RCNN & InceptionV2 & 5 & 0,028 \\
\hline & & 4 & 0,146 \\
\hline & & 3 & 0,290 \\
\hline
\end{tabular}

Tablo 4. TSG'nün 3. seviyesinin farklı boyutlarda elde edilen görüntü örnekleri

\begin{tabular}{|c|c|c|c|}
\hline $\begin{array}{c}\text { Çözünürlük } \\
\text { Seviyesi }\end{array}$ & Görüntü Boyutu & Histopatolojik Görüntü & Maske \\
\hline 3. & $256 \times 256$ & & \\
\hline 3. & $512 \times 512$ & & \\
\hline 3. & $1024 \times 1024$ & & \\
\hline
\end{tabular}


Tablo 5. Görüntü boyutlarına göre değerlendirme sonuçları

\begin{tabular}{c|c}
\hline Görüntü Boyutu & mAP@0.50 IOU \\
\hline $256 \times 256$ & 0,401 \\
\hline $512 \times 512$ & 0,354 \\
\hline $1024 \times 1024$ & 0,184 \\
\hline
\end{tabular}

\section{Deneysel Sonuçlar}

Kullanılan nesne tespit ve bölütleme algoritmalarının sonuçları, HMS\&MIT yöntem sonuçlarıyla kıyaslanmıştır. Faster RCNN ve Mask RCNN algoritmaları TSG'lerinin 3. seviye 256x256 boyutlu veri setinde en yüksek başarım elde etmiştir. Slayt tabanlı ve lezyon tabanlı değerlendirmeler için bu eğitilmiş mimariler kullanılmıştır. TSG'den 256x256 boyutlu pencere gezdirilerek elde edilen görüntüler mimarilere verilerek mimarilerden tümör tahmin çıkışları elde edilmiştir Tümör tahmin çıkışları birleştirilerek tüm slayttın 3. seviye tümör olasılık haritası elde edilmiștir

Sonraki aşamada HMS\&MIT yönteminin geliştirdiği teknik kullanılarak mimarilerin sonuçları kıyaslanmıştır. Olasılık haritaları TSG'nün 7. seviyesine indirgenmiș ve kıyaslama yapılmıştır. Yöntemin değerlendirme tekniği Bölüm 2.3 detaylı anlatılmıştır.
Kısıtlı olanaklardan dolayı eğitim seti için 15 Tümör ve 15 Normal TSG, test seti için 18 TSG kullanılmıştır. Tablo 6'de slayt tabanlı değerlendirme sonuçları verilmiştir. Slayt tabanlı değerlendirme de Mask RCNN sonucu HMS\&MIT sonucuna çok yakın bir değer elde edildiği gözlenmiştir. Tablo 7'de lezyon tabanlı değerlendirme sonuçları verilmiştir. Lezyon tabanlı değerlendirme sonuçları incelendiğinde genel olarak bütün algoritmaların başarısız sonuçlar verdiği gözlenmiştir. Algoritmaların değerlendirmesinde kullanılan TSG sayısının az olması başarım oranını etkilemektedir.

Bir başka analiz de algoritmaların bir TSG için harcadıkları ortalama yürütme süresi hesaplanmıştır. Tablo 8'de hesaplanma süresi verilmiştir. TSG'nün 0 . seviye çalışan HMS\&MIT yöntemi bir TSG için en uzun süreyi harcamaktadır.

Tablo 6. Slayt Tabanlı değerlendirme sonuçları

\begin{tabular}{c|c}
\hline Metotlar & Slayt Tabanlı Değerlendirme-AUC \\
\hline HMS \& MIT & 0,589 \\
\hline Faster RCNN-3.seviye 256x256 & 0,535 \\
\hline Mask RCNN-3.seviye 256x256 & 0,571 \\
\hline
\end{tabular}

Tablo 7. Lezyon Tabanlı değerlendirme sonuçları

\begin{tabular}{c|c}
\hline Metotlar & Lezyon Tabanlı Değerlendirme (FROC) \\
\hline HMS \& MIT & 0,033 \\
\hline Faster RCNN-3.seviye 256x256 & 0,042 \\
\hline Mask RCNN-3.seviye 256x256 & 0,063 \\
\hline
\end{tabular}

Tablo 8. Bir tane TSG maskesi üretmek için harcanan ortalama süre

\begin{tabular}{c|c}
\hline Metotlar & Süre (Saat) \\
\hline HMS \& MIT & 6.39 \\
\hline Faster RCNN-3.seviye 256x256 & 0.54 \\
\hline Mask RCNN-3.seviye 256x256 & 2.79 \\
\hline
\end{tabular}

HMS\&MIT geliştirdiği yöntem, 0 . seviyede alınan görüntüler için tümör olma olasılığına göre tek bir çıkış değeri üretmektedir. Oluşan tümör olasılık haritası TSG'nün 7. seviyesine denk gelmektedir. Tümör olasılık haritası kullanılarak 3. seviyede tümör sınır çizimini ile Mask RCNN tümör sınır çizim sonucu karşılaştırıldığında Mask RCNN daha başarılı sonuç verdiği Şekil 4'te görüntülenmektedir.

Şekil 4'te birinci sütunda referans görüntüsü, tümörlü alanlar yeşil renktedir. İkinci sütun HMS\&MIT yöntem sonucu ve üçüncü sütun Mask RCNN sonucunu verilmektedir. Kırmızı alanlar mimarilerin tümör tahmin sonuçlarıdır. 

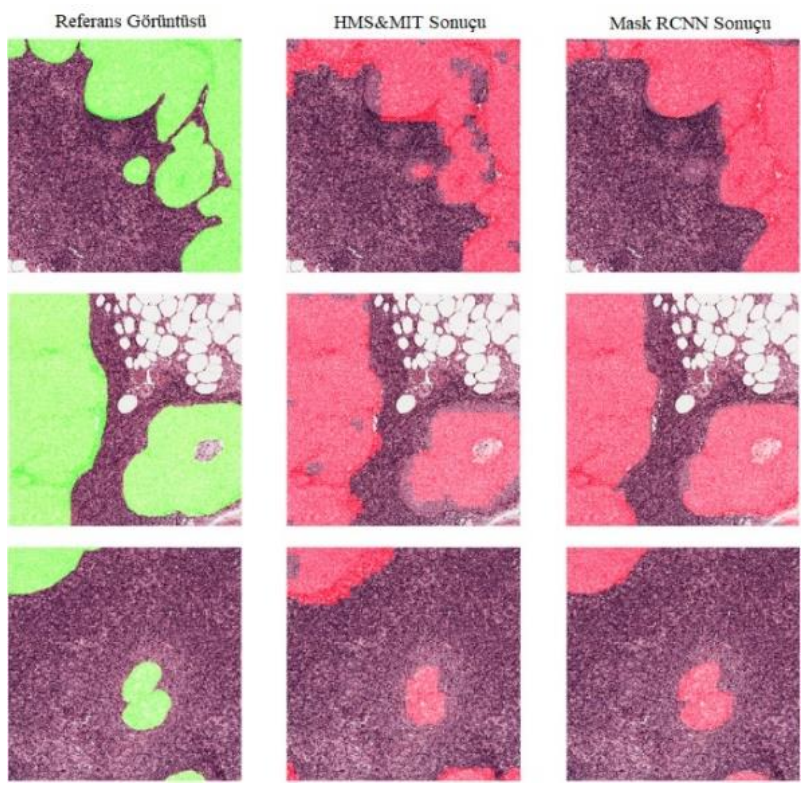

Şekil 4- Birinci sütunda referans görüntüsü, tümörlü alanlar yeşil renktedir. Ikkinci sütunda HMS\&MIT yöntem sonucu ve üçüncü sütunda Mask RCNN sonucu verilmektedir (Kırmızı alanlar mimarilerin tümör tahmin sonuçlarıdır).

\section{Sonuçlar}

CAMELYON16 veri seti kullanılarak TSG'lerinde tümör tespit çalışmalarında, 2017 yılında başarılı olan HMS\&MIT ile görüntü tespit mimarilerinde Faster RCNN ve görüntü tespit ve bölütleme yapan Mask RCNN derin öğrenme algoritmaları kullanılarak karşılaştırma yapılmıştır.

Yapılan çalışmada, Faster RCNN TSG'lerinin farklı görüntü seviyelerinde (3., 4. ve 5. çözünürlük seviyeler) sabit boyutlu (256x256) görüntülerden oluşturulan veri seti kullanılarak tümör tespit başarımı değerlendirilmiştir. Görüntülerin boyutlarının büyüklüğü nedeniyle sadece düşük çözünürlükteki üç seviye sonuçları karşılaştırılmıştır. Karşılaştırmada 3. seviyeden oluşturulan veri seti tümör tespitinde 4 . ve 5. çözünürlük seviye veri setlerine göre daha başarılı sonuçlar vermiştir. Mimarinin yüksek çözünürlüğe sahip görüntülerde doku farklılıkları daha iyi bir şekilde analiz edildiği tespit edilmiştir.

Mask RCNN, anlamsal bölütleme ve nesne tespiti yapan derin öğrenme algoritması ise TSG'nün 3. çözünürlük seviyesinden alınan farklı boyut $(256 \times 256,512 \times 512$ ve $1024 \times 1024)$ görüntüler ile oluşturulan veri setleri kullanılarak başarımı değerlendirilmiştir. $256 \times 256$ boyutlu veri seti sonuçları $512 \times 512$ ve $1024 \times 1024$ boyutlu sonuçlara göre başarılı olduğu tespit edilmiştir.

Son olarak mimarilerin sonuçlarının karşılaştırılması yapılmıştır. Faster RCNN ve Mask RCNN TGS'nin 3. seviye $256 \times 256$ boyutlu görüntülerden oluşturulan veri setinde en başarılı sonucu elde ettikleri için karşıllaştırmada bu eğitilmiş modeller kullanılmıștır. HMS\&MIT, Faster RCNN ve Mask RCNN yöntemleri 18 tane TSG uygulanmış slayt tabanlı değerlendirmede 0 . seviyede (en yüksek çözünürlük seviyesi) çalışan HMS\&MIT başarılı olmuştur. Slayt tabanlı değerlendirmede Mask RCNN 3. seviyede (düşük çözünürlük seviyesi) çalışmış olmasına rağmen HMS\&MIT yöntemine yakın bir sonuç elde edilmiştir. HMS\&MIT yöntemi başarılı olmasına rağmen bir TSG'nün ortalama işlenme süreleri karşılaştırıldığında en hantal yöntem olduğu gözlenmiştir. e-ISSN: 2148-2683
Medikal görüntü işlemlerinde geliştirilen yöntemin doğru analiz yapması önemli bir unsurdur. Aynı zamanda yöntemin hızlı sonuç vermesi de istenen bir durumdur.

Mask RCNN ile elde edilen tümör sınır çizimi başarılı sonuçlar vermektedir. Gelecek çalışmalarda daha üst çözünürlük seviyelerinden oluşturulan veri setleri kullanılarak mimarilerin (Mask RCNN, Faster RCNN) başarıları test edilebilir. Daha hızlı ve doğru sonuçlar elde edilebilir.

\section{Kaynakça}

American Cancer Society. (2019). Surveillance Research, 5. Retrieved from https://www.cancer.org/content/dam/cancer$\mathrm{org} / \mathrm{research} /$ cancer-facts-and-statistics/annual-cancer-factsand-figures/2019/cancer-facts-and-figures-2019.pdf

Babak Ehteshami, B., Geert, L., Nadya, T., Irene, O.-H., André, H., Nico, K., \& Jeroen A W M, V. D. L. (2016). Stain specific standardization of whole-slide histopathological images. IEEE Transactions on Medical Imaging, 35(2), 404-415. Retrieved from https://ieeexplore.ieee.org/abstract/document/7243333/

Bejnordi, B. E., Litjens, G., Hermsen, M., Karssemeijer, N., \& van der Laak, J. A. W. M. (2015). A multi-scale superpixel classification approach to the detection of regions of interest in whole slide histopathology images. Medical Imaging 2015: Digital Pathology, 9420, 94200H.

Celik, Y., Talo, M., Yildirim, O., Karabatak, M., \& Acharya, U. R. (2020). Automated Invasive Ductal Carcinoma Detection Based Using Deep Transfer Learning with Whole-Slide Images. Pattern Recognition Letters. Elsevier B.V. Retrieved from https://doi.org/10.1016/j.patrec.2020.03.011

Chollet, F. (2017). Xception: Deep Learning with Depthwise Separable Convolutions. 2017 IEEE Conference on Computer Vision and Pattern Recognition (CVPR) (pp. 1800-1807). IEEE. Retrieved from http://ieeexplore.ieee.org/document/8099678/

Ehteshami Bejnordi, B., Balkenhol, M., Litjens, G., Holland, R., Bult, P., Karssemeijer, N., \& Van Der Laak, J. A. W. M. (2016). Automated Detection of DCIS in Whole-Slide H\&E Stained Breast Histopathology Images. IEEE Transactions on Medical Imaging, 35(9), 2141-2150.

Ehteshami Bejnordi, B., Veta, M., Johannes van Diest, P., van Ginneken, B., Karssemeijer, N., Litjens, G., van der Laak, J. A. W. M., et al. (2017). Diagnostic Assessment of Deep Learning Algorithms for Detection of Lymph Node Metastases in Women With Breast Cancer. JAMA, 318(22), 2199. Retrieved from http://jama.jamanetwork.com/article.aspx?doi=10.1001/jam a.2017.14585

Fan, J., Upadhye, S., \& Worster, A. (2006). Understanding receiver operating characteristic (ROC) curves. CJEM, 8(01), 19-20. Retrieved from https://www.cambridge.org/core/product/identifier/S148180 3500013336/type/journal_article

Girshick, R. (2015). Fast R-CNN. Proceedings of the IEEE International Conference on Computer Vision, 2015 Inter, 1440-1448.

Girshick, R., Donahue, J., Darrell, T., \& Malik, J. (2016). Region-Based Convolutional Networks for Accurate Object Detection and Segmentation. IEEE Transactions on Pattern Analysis and Machine Intelligence, 38(1), 142-158. Retrieved http://ieeexplore.ieee.org/document/7112511/ 
Guo, Z., Liu, H., Ni, H., Wang, X., Su, M., Guo, W., Wang, K., et al. (2019). A Fast and Refined Cancer Regions Segmentation Framework in Whole-slide Breast Pathological Images. Scientific Reports, 9(1), 1-10. Springer US. Retrieved from http://dx.doi.org/10.1038/s41598-01837492-9

Gupta, V., \& Bhavsar, A. (2018). Sequential modeling of deep features for breast cancer histopathological image classification. IEEE Computer Society Conference on Computer Vision and Pattern Recognition Workshops, 2018June, 2335-2342.

He, K., Gkioxari, G., Dollár, P., \& Girshick, R. (2017). Mask RCNN. 2017 IEEE International Conference on Computer Vision (ICCV), 2017-Octob, 2980-2988. IEEE. Retrieved from http://ieeexplore.ieee.org/document/8237584/

Ishikawa, M., Okamoto, C., Shinoda, K., Komagata, H., Iwamoto, C., Ohuchida, K., Hashizume, M., et al. (2019). Detection of pancreatic tumor cell nuclei via a hyperspectral analysis of pathological slides based on stain spectra. Biomedical Optics Express, 10(9), 4568. Retrieved from https://www.osapublishing.org/abstract.cfm?URI=boe-10-94568

Reis, S., Gazinska, P., Hipwell, J. H., Mertzanidou, T., Naidoo, K., Williams, N., Pinder, S., et al. (2017). Automated Classification of Breast Cancer Stroma Maturity from Histological Images. IEEE Transactions on Biomedical Engineering, 64(10), 2344-2352.

Ren, S., He, K., Girshick, R., \& Sun, J. (2015). Faster R-CNN: Towards Real-Time Object Detection with Region Proposal Networks. Computer Vision and Pattern Recognition, 1-14. Retrieved from https://arxiv.org/abs/1506.01497

Riaz, N., Wolden, S. L., Gelblum, D. Y., \& Eric, J. (2016). Multi-instance Multi-label Learning for Multi-class Classification of Whole Slide Breast Histopathology Images, 118(24), 6072-6078.

Samah, A. A., Fauzi, M. F. A., \& Mansor, S. (2017). Classification of benign and malignant tumors in histopathology images. Proceedings of the 2017 IEEE International Conference on Signal and Image Processing Applications, ICSIPA 2017, 102-106.

Song, Y., Zou, J. J., Chang, H., \& Cai, W. (2017). Adapting fisher vectors for histopathology image classification. Proceedings - International Symposium on Biomedical Imaging, 600-603. IEEE.

Spanhol, F. A., Oliveira, L. S., Petitjean, C., \& Heutte, L. (2016). A Dataset for Breast Cancer Histopathological Image Classification. IEEE Transactions on Biomedical Engineering, 63(7), 1455-1462.

Verma, R., Sharma, S., Vahadane, A., Kumar, N., Sethi, A., \& Bhargava, S. (2017). A Dataset and a Technique for Generalized Nuclear Segmentation for Computational Pathology. IEEE Transactions on Medical Imaging, 36(7), 1550-1560.

Wan, S., Lee, H. C., Huang, X., Xu, T., Xu, T., Zeng, X., Zhang, Z., et al. (2017). Integrated local binary pattern texture features for classification of breast tissue imaged by optical coherence microscopy. Medical Image Analysis, 38, 104116. Elsevier B.V. Retrieved from http://dx.doi.org/10.1016/j.media.2017.03.002

Wang, D., Khosla, A., Gargeya, R., Irshad, H., \& Beck, A. H. (2016). Deep Learning for Identifying Metastatic Breast Cancer, 1-6. Retrieved from http://arxiv.org/abs/1606.05718

Wang, X., Chen, H., Gan, C., Lin, H., \& Dou, Q. (2018). Weakly
Supervised Learning for Whole Slide Lung Cancer Image Classification. Pdfs.Semanticscholar.Org, (Midl), 1-10. Retrieved from https://pdfs.semanticscholar.org/35d0/998f2c5b53591073d3 6c9e2b0ddc89a496b1.pdf

Wei, J. W., Tafe, L. J., Linnik, Y. A., Vaickus, L. J., Tomita, N., \& Hassanpour, S. (2019). Pathologist-level classification of histologic patterns on resected lung adenocarcinoma slides with deep neural networks. Scientific reports, 9(1), 3358.

Xu, G., Song, Z., Sun, Z., Ku, C., Yang, Z., Liu, C., Wang, S., et al. (2019). CAMEL: A Weakly Supervised Learning Framework for Histopathology Image Segmentation. 2019 IEEE/CVF International Conference on Computer Vision (ICCV) (pp. 10681-10690). IEEE. Retrieved from https://ieeexplore.ieee.org/document/9008367/ 